\title{
Sensitivity and wound healing after hot-iron disbudding in goat kids
}

\author{
Lorenzo Alvarez, ${ }^{1}$ Sarah J. J. Adcock, ${ }^{2}$ and Cassandra B. Tucker ${ }^{2 *}$ \\ ${ }^{1}$ Facultad de Medicina Veterinaria y Zootecnia, Universidad Nacional Autónoma de México, Ciudad de México, 04510 Mexico \\ ${ }^{2}$ Center for Animal Welfare, Department of Animal Science, University of California, Davis 95616
}

\section{ABSTRACT}

Hot-iron disbudding in goat kids causes acute pain and tissue damage. However, the duration of healing and wound sensitivity is unknown. We assessed wound healing and pain sensitivity in 18 female dairy goat kids disbudded with a heated iron at $10 \mathrm{~d}$ of age (range: $5-15$ d). Pressure algometry was carried out twice a week from d 1 after disbudding to determine the mechanical nociceptive threshold (MNT) in 4 locations on each bud (front, lateral, caudal, and middle). At the same time, digital and infrared images of the wounds were used to visually and thermally describe the healing process. Wounds were visually scored daily for the presence of 7 tissue types: attached necrotic tissue, detached necrotic tissue, burns outside the necrotic ring, exudate, granulation, crust, and epithelium. All data were taken until epithelium was present for 4 consecutive days. Necrotic tissue detached completely from the scalp $26 \pm 5 \mathrm{~d}$ after the procedure (mean $\pm \mathrm{SD}$; range: $17-43 \mathrm{~d}$ ), and wounds took $50 \pm 8 \mathrm{~d}(35-63 \mathrm{~d})$ to re-epithelialize. Wounds were more sensitive at all stages of the healing process compared with re-epithelialized tissue. The caudal and middle locations were the most- and leastsensitive test sites $(1.24 \pm 0.10$ and $1.90 \pm 0.10 \mathrm{~N}$, respectively; mean $\pm \mathrm{SE}$ ). Goats became less responsive to stimulation as their wounds decreased in size. Sensitivity did not differ between left and right sides of the head. Maximum surface temperature of necrotic tissue, when present, tended to be higher than that of epithelium $\left(38.8 \pm 0.2\right.$ vs. $\left.38.1 \pm 0.2^{\circ} \mathrm{C}\right)$; temperature did not differ among other tissue types. Our results indicate that hot-iron disbudding wounds in goats take, on average 7 , wk to re-epithelialize (35-63 d) and are painful throughout this time, raising additional welfare concerns about this procedure.

Key words: cautery dehorning, animal welfare, pressure algometry, mechanical nociceptive threshold

Received November 27, 2018.

Accepted June 27, 2019.

*Corresponding author: cbtucker@ucdavis.edu

\section{INTRODUCTION}

Disbudding, the destruction of horn bud germinal tissue to prevent horn growth, is a common practice on dairy farms worldwide (Valdmanis et al., 2007; Hötzel et al., 2014; Cozzi et al., 2015; Winder et al., 2016). Although several methods are available, the horn buds of goat kids (Al-Sobayil, 2007; Valdmanis et al., 2007) and calves (Fulwider et al., 2008; Cozzi et al., 2015) are commonly prevented from growing by cauterization with a heated iron. Regardless of the selected method, the procedure is painful and a serious welfare concern (Alvarez and Gutiérrez, 2010; Knierim et al., 2015; Hempstead et al., 2018a,b).

Pain associated with hot-iron disbudding has been quantified in several ways, using physiological and behavioral changes (Alvarez et al., 2009; Alvarez and Gutiérrez, 2010; Heinrich et al., 2010; Allen et al., 2013; Alvarez et al., 2015; Hempstead et al., 2017). Pain is also evaluated with mechanical stimulation of the local tissue to assess the mechanical nociceptive threshold (MNT), using von Frey monofilaments (e.g., Mintline et al., 2013; Mirra et al., 2018) or pressure algometry (e.g., De Heus et al., 2010). In the latter, pressure is applied and gradually increased until an avoidance reaction is shown (De Heus et al., 2010); at this point, it is said that the MNT is reached. In disbudded calves, MNT around the horn bud is lower than baseline or control levels, indicating that the wounds are painful to pressure (reviewed in Adcock and Tucker, 2018a). Hempstead et al. (2018c) demonstrated that goat kids are more sensitive to algometry $1 \mathrm{~h}$ after hot-iron, liquid nitrogen, or caustic paste disbudding compared with control animals.

Welfare may also be compromised for several weeks during the healing process. In disbudded calves, tissue remains severely damaged for at least 3 or 4 wk (Huebner et al., 2017) and complete re-epithelialization takes from 6 to 13 wk (Adcock and Tucker, 2018b; Adcock et al., 2019). Throughout this time, wounds are more sensitive to pressure algometry than newly re-epithelialized tissue (Adcock and Tucker, 2018b). Others have reported increased sensitivity for at least $14 \mathrm{wk}$ after the procedure in dairy calves (Casoni et al., 2019). 
Little is known about the welfare implications of hot-iron disbudding in goat kids beyond the first few hours after the procedure. Others have evaluated horn regrowth 2 to 3 mo after hot-iron (Nfor et al., 2016; Hempstead et al., 2018d) and clove oil (Molaei et al., 2015; Hempstead et al., 2018d) disbudding. Hempstead et al. (2018b) described tissue damage 6 wk after different disbudding methods and found that wounds were still not completely healed at this time. To date, no studies have evaluated pain sensitivity during the healing period in disbudded goat kids. Therefore, our objective was to describe the healing process and wound sensitivity after hot-iron disbudding in female dairy goat kids.

\section{MATERIALS AND METHODS}

We carried out this study from April to July 2017 at the University of California Davis Goat Facility. The University of California Davis Institutional Animal Care and Use Committee approved all procedures (IACUC, protocol \#19767).

\section{Animals and Housing}

Eighteen female dairy goat kids born between April 4 and May 10, 2017, were included (French Alpine: 10; La Mancha: 6; and Saanen: 2). Sample size was based on availability of animals at the facility. At the time of disbudding, kids were $10 \pm 3$ d old (mean $\pm \mathrm{SD}$; range $5-15 \mathrm{~d})$ and weighed $5.1 \pm 0.6 \mathrm{~kg}(4.1-6.5 \mathrm{~kg})$.

All kids were removed from their mothers at birth and fed with heat-treated colostrum within the first 12 $\mathrm{h}$. Kids were kept in groups of 2 to 4 in $2-\mathrm{m}^{2}$ cardboard boxes until 2 wk of age. These boxes were bedded with oat straw and heated with lamps when needed. After this period, kids were placed in 2 disinfected group pens, with at least $2 \mathrm{~m}^{2}$ per kid. Pasteurized goat milk was fed ad libitum every $4 \mathrm{~h}$ during the first week of age, every $6 \mathrm{~h}$ between 2 and $3 \mathrm{wk}$, and every $8 \mathrm{~h}$ between 3 and 4 wk. Starting at 4 wk of age, milk was offered ad libitum at 0700 and $1900 \mathrm{~h}$ until weaning at approximately $90 \mathrm{~d}$ of age. A pellet mix was offered ad libitum beginning at 3 to 4 wk of age. Clean water buckets were provided daily and dry straw bedding was replaced every third day. There was an overall ADG of $202 \pm 175 \mathrm{~g}$ (mean $\pm \mathrm{SD}$ ) during the experimental period.

\section{Disbudding}

During disbudding, kids were restrained using a wooden "disbudding box" (68 cm long, $50 \mathrm{~cm}$ high, 22 $\mathrm{cm}$ wide). Before disbudding, a $4-$ to $4.5-\mathrm{cm}^{2}$ square patch of hair was clipped around the center of each horn bud with an electric razor (Super AGR+ 63855, Andis Company, Sturtevant, WI). An electric dehorner (Rhinehart X-30, Rhinehart Development Corp., Spencerville, IN) was used to cauterize the horn bud. To avoid a decrease in iron temperature between the first and second bud, 2 dehorners were used, 1 per bud. The right bud was always cauterized first. The iron was applied to each horn bud with circular movements and light downward pressure until a copper ring of cauterized tissue was present. The iron was applied $3 \pm 1$ times to each bud for a total of $10 \pm 2 \mathrm{~s}$ (mean $\pm \mathrm{SD}$ ). The cauterized horn bud was not removed, following the farm's standard operating procedure (SOP). We recorded iron temperature using an infrared thermometer (model 42512, Extech Instruments Corp., Nashua, $\mathrm{NH}$ ) immediately before the first contact on each bud (mean \pm SD; left: $501 \pm 28^{\circ} \mathrm{C}$; right: $501 \pm 33^{\circ} \mathrm{C}$ ). No pain relief was provided, following the farm's SOP. One experienced operator performed all disbudding procedures.

\section{Data Collection}

Direct, Visual Observation. Wounds were visually evaluated daily by 4 trained observers to describe the healing process (0/1 scoring; Figure 1; inter-observer reliability: Cohen's kappa $\geq 0.70)$. This scoring system was previously used in calves (Adcock and Tucker, 2018b). For observations, one person held the kid while standing in the pen and a trained observer scored the wounds. Scoring continued for each wound until epithelium was present. Re-epithelialization was confirmed by observing the wound over the following 3 consecutive days. Horn regrowth (yes or no) was noted on the last day of data collection for all buds.

Digital and Infrared Images. For these procedures and the others mentioned below, the kid was manually restrained on the lap of a trained assistant, $4 \mathrm{~m}$ outside the pen. The kid's head was gently held by the assistant, but movement by the animal was possible. Kids were blindfolded with a soft cloth to reduce responses to visual cues. We took infrared and digital photos twice a week starting the day after disbudding and until epithelium was present. Images of buds were taken using a digital camera (model D5300, Nikon, Tokyo, Japan). A measuring tape was placed vertically between the buds to quantify wound size over time from the digital photos. Wounds were scored only from direct observations, and the photos were not used for this purpose.

Infrared thermography was used to assess wound temperature during the healing process. Photos of both buds were taken in a shaded area using an infrared 


\begin{tabular}{|c|c|c|c|}
\hline Example & Tissue & Description & $\begin{array}{c}\text { Inter-observer reliability } \\
\text { (Cohen's Kappa) }\end{array}$ \\
\hline & $\begin{array}{l}\text { Attached } \\
\text { necrotic tissue }\end{array}$ & $\begin{array}{l}\text { The edges of the copper ring are } \\
\text { not separated from the scalp }\end{array}$ & $0.92-0.95$ \\
\hline & $\begin{array}{l}\text { Burned tissue } \\
\text { outside the } \\
\text { ring }\end{array}$ & $\begin{array}{l}\text { Hairless patch(es) around the } \\
\text { outside of copper ring; only } \\
\text { observed when attached } \\
\text { necrotic tissue is present }\end{array}$ & $0.80-0.87$ \\
\hline & $\begin{array}{l}\text { Detached } \\
\text { necrotic tissue }\end{array}$ & $\begin{array}{l}\text { The edges outside the copper } \\
\text { ring have started to separate } \\
\text { from the scalp }\end{array}$ & $0.90-0.92$ \\
\hline & Exudate & $\begin{array}{l}\text { Fresh blood; can be moist or } \\
\text { freshly dried (discoloration has } \\
\text { not yet occurred) }\end{array}$ & $0.70-0.76$ \\
\hline & Granulation & $\begin{array}{l}\text { Light red/dark pink, opaque, } \\
\text { bumpy tissue; may be observed } \\
\text { underneath detached necrotic } \\
\text { tissue }\end{array}$ & $0.70-0.73$ \\
\hline & Crust & $\begin{array}{l}\text { Dried exudate; may be present } \\
\text { underneath detached necrotic } \\
\text { tissue; isolated specks (pencil- } \\
\text { tip size) of dried blood are not } \\
\text { counted }\end{array}$ & $0.88-0.91$ \\
\hline & Epithelium & $\begin{array}{l}\text { Layer of translucent skin is } \\
\text { present; the other tissues types } \\
\text { are absent }\end{array}$ & $0.84-0.85$ \\
\hline
\end{tabular}

Figure 1. The scoring system used to evaluate tissue types in disbudding wounds. The range of inter-observer reliability values $(\mathrm{n}=3$ observers compared with 1 gold standard by S. J. J. Adcock) is given for each tissue.

camera (model T430sc, FLIR Systems AB, Taby, Sweden). On the day of disbudding (d 0), we took infrared photos immediately before and after the procedure. The camera was placed approximately $0.5 \mathrm{~m}$ from the head, and the image area was standardized by using a cardboard frame $(7 \times 9 \mathrm{~cm})$ around both wounds. Maximum surface temperature of the bud was determined using image analysis software (FLIR Systems $\mathrm{AB})$. We lost $2 \%$ of photos due to equipment failure.

Pain Sensitivity. We measured MNT twice a week, starting the day after disbudding and until epithelium was observed, using a 4-mm-diameter rubber-tipped algometer (ProdPlus algometer, TopCat Metrology Ltd., Ely, UK). This test was always performed before the digital and infrared images were taken, and began approximately 1.5 to 2 min after restraining the kid. The total time that each kid was restrained for algometry and photography was $10 \pm 4$ min (mean $\pm \mathrm{SD}$ ). One trained person manually operated the algometer, applying pressure on 4 different points per bud, at the edges of the cauterized tissue (Figure 2). The tips of 2 fingers were gently placed on the sides of each point and 
slowly removed and replaced by the algometer tip using a force $<0.01 \mathrm{~N}$. As soon as the kid was still, force was applied at a consistent rate (mean $\pm \mathrm{SD}$ : $0.21 \pm 0.09$ $\mathrm{N} / \mathrm{s}$ ) perpendicular to the skin until a physical response was detected (head movements or vocalization) or a maximum $10 \mathrm{~N}$ of force was reached. If an interruption occurred (e.g., fly landing on the wound or sudden noise), the test was repeated. The algometer operator was always responsible for deciding when the animal responded. In $96 \%$ of tests, responses were recorded as light and quick head movements, and vocalizations were not common ( $4 \%$ of 1,948 tests). The next point was tested immediately after the previous test result was recorded. The order of test sites and side (left, right) was randomized without replacement between kids using computer-generated random numbers. Ten of the kids were tested on the right bud first followed by the left; the opposite was done in the remaining 8 . The order in which animals were tested occurred opportunistically to reduce handling time as kids needed to be restrained for identification.

The algometer readings during each test were video recorded (Panasonic HC-V550, Kadoma, Japan; 2\% of videos missing overall). The rate that force was applied was then quantified from video. Data from tests with rates $<0.1$ or $>0.6 \mathrm{~N} / \mathrm{s}$ were excluded $(10 \%$ of 1,948 tests).

\section{Statistical Analysis}

We compared sensitivity of each damaged tissue type to sensitivity of epithelium using linear mixed models with kid fitted as a random effect ( 1 model $/$ tissue $=6$ models). The MNT values for each kid were averaged over all test days by tissue type, resulting in 1 data point/tissue per kid. Sample sizes for each tissue type differed because some tissues were not observed in all kids (number of data points/tissue: attached necrotic tissue $=18$; burns outside the ring $=11$; detached necrotic tissue $=18$; exudate $=11 ;$ granulation $=18$; crust $=18$ ). If multiple tissues were present in a single wound on the same test day, the MNT values from those tests were included in the calculation of the average MNT for each tissue.

We compared the maximum surface temperature of each damaged tissue type to that of epithelium using the same methods described above but with temperature as the response variable instead of MNT (1 model/ tissue $=6$ models). Maximum surface temperature for each kid was averaged over all test days by tissue type, resulting in the same number of data points for each tissue as described for the MNT analysis.

We used a linear mixed model to assess the effect of test order (1-8; treated as a linear effect), side (left vs. right), and location (front, lateral, caudal, middle) on MNT until the wound had re-epithelialized. Based on visual inspection of the data, the relationships between MNT and side, location, and test order appeared consistent through time. Therefore, MNT values for each kid were averaged over all test days by test site, resulting in 8 data points/kid. We also examined the effect of wound size on MNT until re-epithelialization with a linear mixed model (14-30 data points/kid). A linear mixed model was used to test the effect of days since disbudding and side on maximum surface temperature over a 50-d healing period, after which time the majority of wounds had re-epithelialized and there were too few remaining to allow reliable interpretations of the data past this cut-off. Kid was fitted as a random effect in all models. If an effect was identified in the models $(P<0.10)$, we performed pairwise comparisons using Tukey's method with the "lsmeans" package (Lenth, 2016).

All models were fit using the restricted maximum likelihood (REML) method implemented in the "nlme" (Pinheiro et al., 2017) package in $\mathrm{R}$, version 3.4.1 (R Core Team, 2015). The containment method was used to estimate degrees of freedom. Residuals versus fit plots and Q-Q plots were visually inspected to confirm homogeneity of variance and normality, respectively, for all models. Least squares means and standard errors are reported, unless noted otherwise. The right side of 1 kid was excluded from the analysis due to early horn regrowth that prevented wound healing.

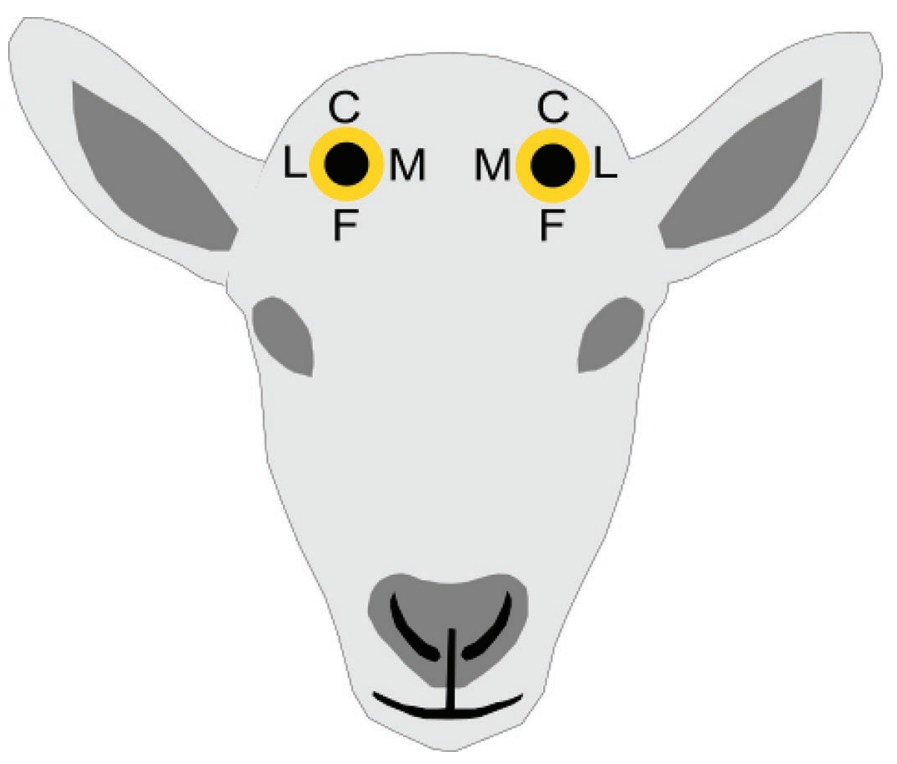

Figure 2. Pressure algometry sites along the edge of each wound or horn bud (control). $\mathrm{L}=$ lateral; $\mathrm{C}=$ caudal; $\mathrm{M}=$ middle; $\mathrm{F}=$ front. Illustration by Jason Miszaniec, University of California, Davis. 


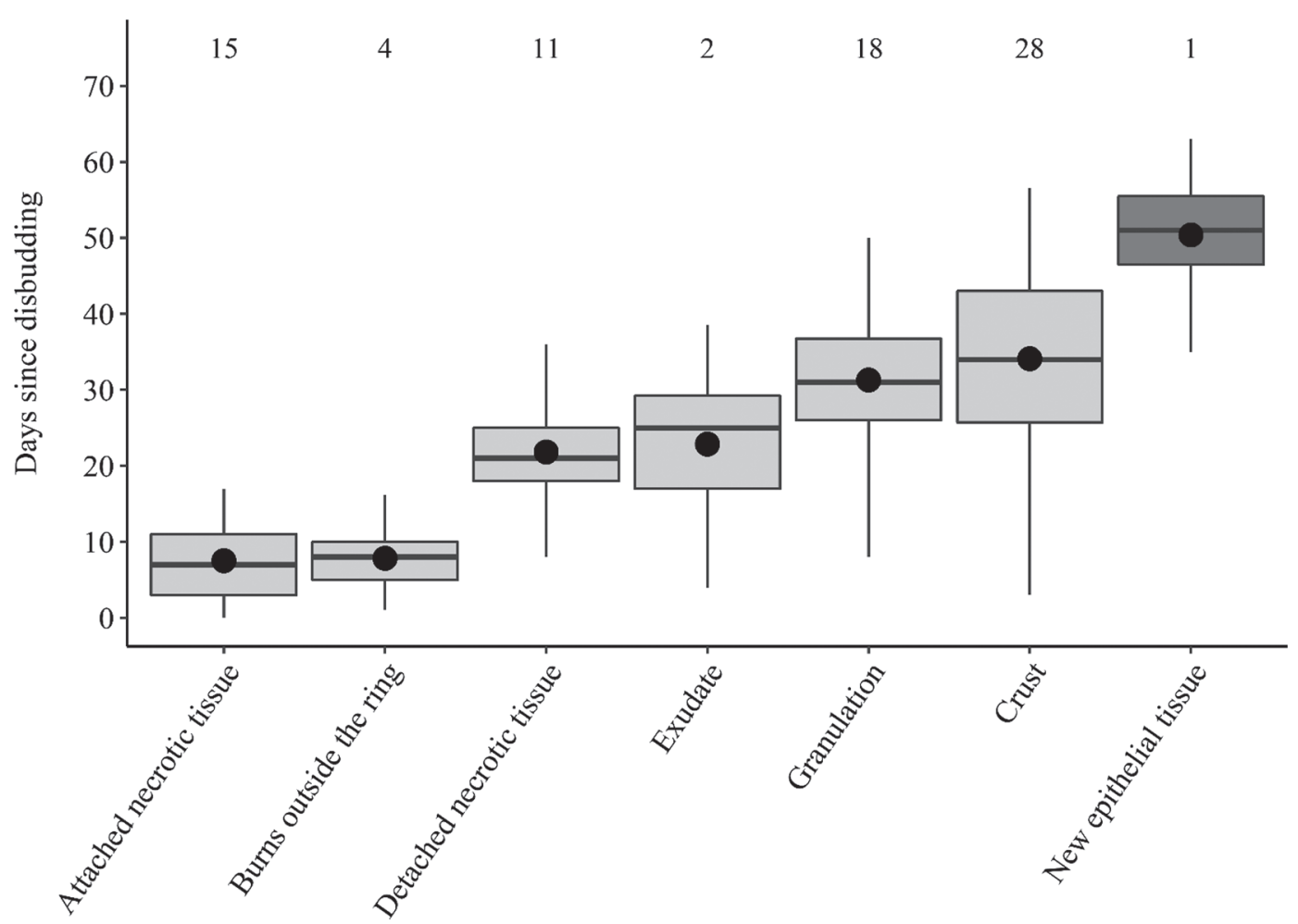

Figure 3. Days each tissue was observed relative to disbudding. Whiskers indicate the 2nd and 98th percentiles and circles indicate arithmetic means. The top and bottom of the boxes indicate the 75 th and 25 th quartiles, respectively. The average number of days the tissue was observed in a single wound is indicated above each box.

\section{RESULTS}

\section{Healing}

Wounds took $50 \pm 8 \mathrm{~d}$ (mean $\pm \mathrm{SD}$ ) to re-epithelialize (range 35-63 d). Necrotic tissue detached completely after $26 \pm 5 \mathrm{~d}(17-43 \mathrm{~d})$. Figure 3 shows when different tissues were present during the healing period. We observed horn regrowth to varying degrees after wound healing in all kids except one (Supplemental Figure S1; https://doi.org/10.3168/jds.2018-16062).

\section{Pain Sensitivity}

All animals responded in all tests before reaching the cut-off level. All tissues present during wound healing were more sensitive than epithelium (attached necrotic tissue: $F_{1,17}=28.04$; burns outside the ring: $F_{1,10}=$ 17.89; detached necrotic tissue: $F_{1,17}=36.67$; exudate: $F_{1,10}=57.83 ;$ granulation: $F_{1,17}=17.59$; crust: $F_{1,17}$ $=32.61 ; P \leq 0.002 ;$ Figure 4$)$. The caudal edge was most sensitive, and the middle edge was least sensitive (caudal: $1.24 \pm 0.10 \mathrm{~N}$; front: $1.50 \pm 0.10 \mathrm{~N}$; lateral: $1.55 \pm 0.10 \mathrm{~N} ;$ middle: $1.90 \pm 0.10 \mathrm{~N} ; F_{3,124}=19.52$; $P<0.001)$. The amount of force required to elicit a response increased over the 8 tests (test order: $F_{1,124}$
$=8.52 ; P=0.004 ;$ Figure 5$)$. In a post hoc analysis comparing the first test to each of the others, MNT was higher in the third and seventh tests (Figure 5). Sensitivity did not differ between left and right wounds (left: $1.57 \pm 0.09 \mathrm{~N}$; right: $1.53 \pm 0.09 \mathrm{~N} ; F_{1,124}=0.69 ; P$ $=0.407)$. Sensitivity decreased as the wounds became smaller $\left(F_{1,444}=73.81, P<0.001\right.$; Figure 6$)$.

\section{Infrared Thermography}

Maximum surface temperature was higher on d 0 than on all following days $\left(\mathrm{d}\right.$ 0: $42.2 \pm 0.2^{\circ} \mathrm{C}$; all other days: $\left.38.1 \pm 0.2^{\circ} \mathrm{C} ; F_{1,490}=25.29 ; P<0.001\right)$. Side did not affect surface temperature $\left(F_{1,490}=0.00 ; P=\right.$ $0.973)$, nor did it interact with days since disbudding $\left(F_{1,490}=2.38 ; P=0.124\right)$. Attached necrotic tissue tended to be hotter than epithelium $\left(F_{1,17}=3.84 ; P=\right.$ 0.067; Figure 7). Temperatures did not differ between other damaged tissues and epithelium $\left(F_{1,10-17} \leq 0.13\right.$; $P \geq 0.724$; Figure 7).

\section{DISCUSSION}

The present study evaluated healing and pain sensitivity after hot-iron disbudding in goat kids. We observed that the wounds took 7 wk to heal and were 
painful throughout that time. In other studies that have assessed long-term effects of disbudding, observations were limited to monitoring horn regrowth, and the duration of tissue damage was not reported (Molaei et al., 2015; Nfor et al., 2016). Hempstead et al. (2018b) evaluated tissue damage on $\mathrm{d} 1,2$, and 7 , and wk 6 after disbudding, and did not observe complete wound closure in that period. In our study, visual scoring was done daily and continued until a layer of epithelium was present.

Hot-iron disbudding causes immediate protein denaturation, degradation, and coagulation, leading to tissue necrosis (Rowan et al., 2015). The necrotic tissue is degraded during the inflammatory phase, in our case falling off, on average, $26 \mathrm{~d}$ after disbudding. In human burn patients, excising necrotic tissue accelerates wound healing (David and Chiu, 2018). In our study, we left the cauterized bud intact, but others have removed this tissue during disbudding (Hempstead et al., 2018b). It is unknown how removing this tissue affects wound healing or sensitivity.

Eleven kids had secondary burns outside the necrotic tissue. Adcock and Tucker (2018b) found similar lesions in calves and suggested they may be due to skin exposure from clipping the hair around the bud. It is unclear whether hair protects against secondary burns, and whether clipping is advisable. Iron temperature may also explain these secondary burns, as a hotter iron would cause more damage around the contact area. Others have successfully disbudded using a cooler iron $\left(295-326^{\circ} \mathrm{C}\right.$; Nfor et al., 2016), but the optimal temperature and application time for preventing horn growth while minimizing tissue damage is unknown.

Partial horn regrowth was observed in 17 of 18 kids. Regrowth occurs when the germinal corium is incompletely cauterized (Smith and Sherman, 2009). This regrowth, known as a scur, is considered unaesthetic and in some cases may grow misshapenly and press against the skull or eyes of the adult goat (Smith and Sherman, 2009). In our study, early regrowth interfered with healing in one kid. Others reported no regrowth 2 mo (Nfor et al., 2016) or 6 wk (Hempstead et al., 2018b) after hot-iron disbudding. It is also not clear whether the regrowth we observed will result in a full scur or remain as a small amount of horn tissue within the wound bed. As mentioned before, we did not remove the cauterized bud, which may have affected the occurrence of horn regrowth; others, such as Hempstead et al. (2018b), flicked the bud out during the procedure and observed no regrowth. There is recent evidence that flicking the bud out is more effective at preventing horn regrowth compared with leaving it intact in kids ( 77 vs. $20 \%$ suc-

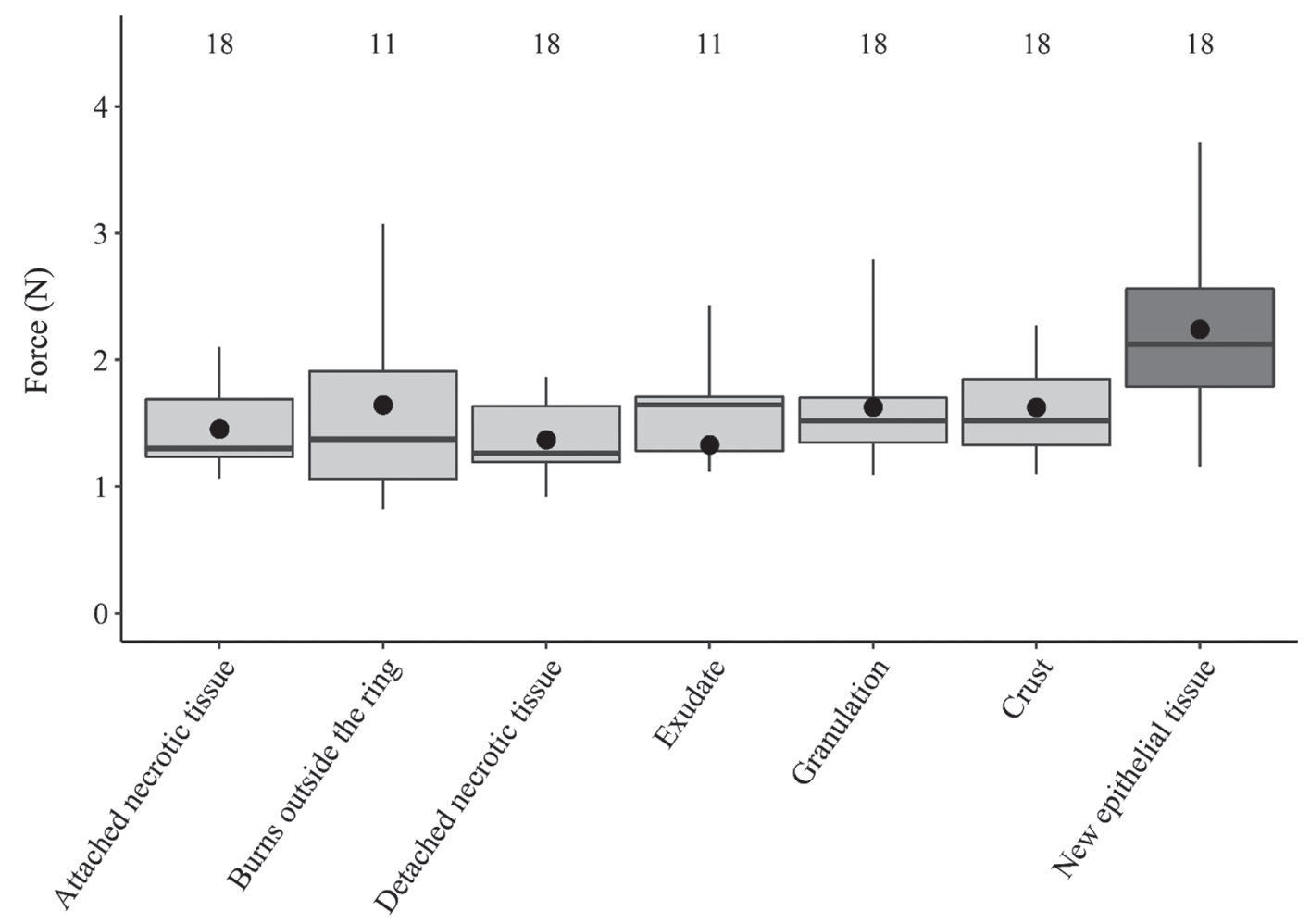

Figure 4. Disbudding wound sensitivity (force, N) for each of the 7 tissue types present in the wound bed. Whiskers indicate the 2nd and 98th percentiles and circles indicate least squares means. The top and bottom of the boxes indicate the 75th and 25th quartiles, respectively. Each tissue was observed in all kids, except for burns outside the ring and exudate (sample size indicated above each box). 
cess rate; Hempstead et al., 2018d) and calves (Sutherland et al., 2019), but the welfare implications of this method have not been investigated.

As expected, wound surface temperature was $3.1^{\circ} \mathrm{C}$ higher on $\mathrm{d} 0$ than on all other days, as these images were taken immediately after disbudding, when the area was still hot due to iron contact. Attached necrotic tissue, which might be associated with the inflammatory phase, tended to be hotter than epithelium; the temperature of other tissue types did not differ from that of epithelium. Hempstead et al. (2018b) reported that the skin surrounding horn buds was warmer in hot-iron disbudded versus sham-disbudded kids after $72 \mathrm{~h}$, although no differences were observed during the first $48 \mathrm{~h}$. Similar results were found by Van der Saag et al. (2018) in amputation-dehorned calves on d 3 and 7 compared with d 1 . Others, however, found no differences between disbudded and nondisbudded tissue after $24 \mathrm{~h}$ (Mirra et al., 2018) or 3 wk (Adcock and Tucker, 2018b). We cannot exclude the potential influence of ambient temperature on our results. However, wound temperature decreased $0.8^{\circ} \mathrm{C}$ from April to July despite increasing ambient temperature, suggesting that an environmental influence may be negligible. Infrared thermography measures thermal emission throughout the layers of the skin; when more blood vessels are injured, deeper under the skin, there is less tissue perfusion and thermal emission (Devgan et al., 2006; Miccio et al., 2016). In humans, thermography allows improved clinical assessment of burn depth, severity, and outcome (Hardwicke et al., 2013; Medina-Preciado et al., 2013). In farm animals, infrared thermography has been used to identify inflammation and blood flow in diverse cases such as ear infections (Karakuş et al., 2015), hoof lesions (Alsaaod and Büscher, 2012; Harris-Bridge et al., 2018), and mastitis (Polat et al., 2010). It remains unclear what infrared thermography tells us about the healing process for disbudding burns.

Sensitivity corresponded to wound size and was almost twice as high when damaged tissue was present compared with epithelium. Adcock and Tucker (2018b) reported a similar MNT pattern for hot-iron disbudding wounds in calves during a 9-wk healing period. The only other study to evaluate MNT after hot-iron disbudding in goat kids found increased sensitivity $1 \mathrm{~h}$ after the procedure relative to control animals (Hempstead et al., 2018c). Increased sensitivity indicates that the wounds are painful when stimulated, but further investigation is needed to determine whether disbudded kids experience ongoing pain in the absence of stimulation during healing. In addition to hypersensitivity to mechanical stimuli, itching and ongoing pain are almost

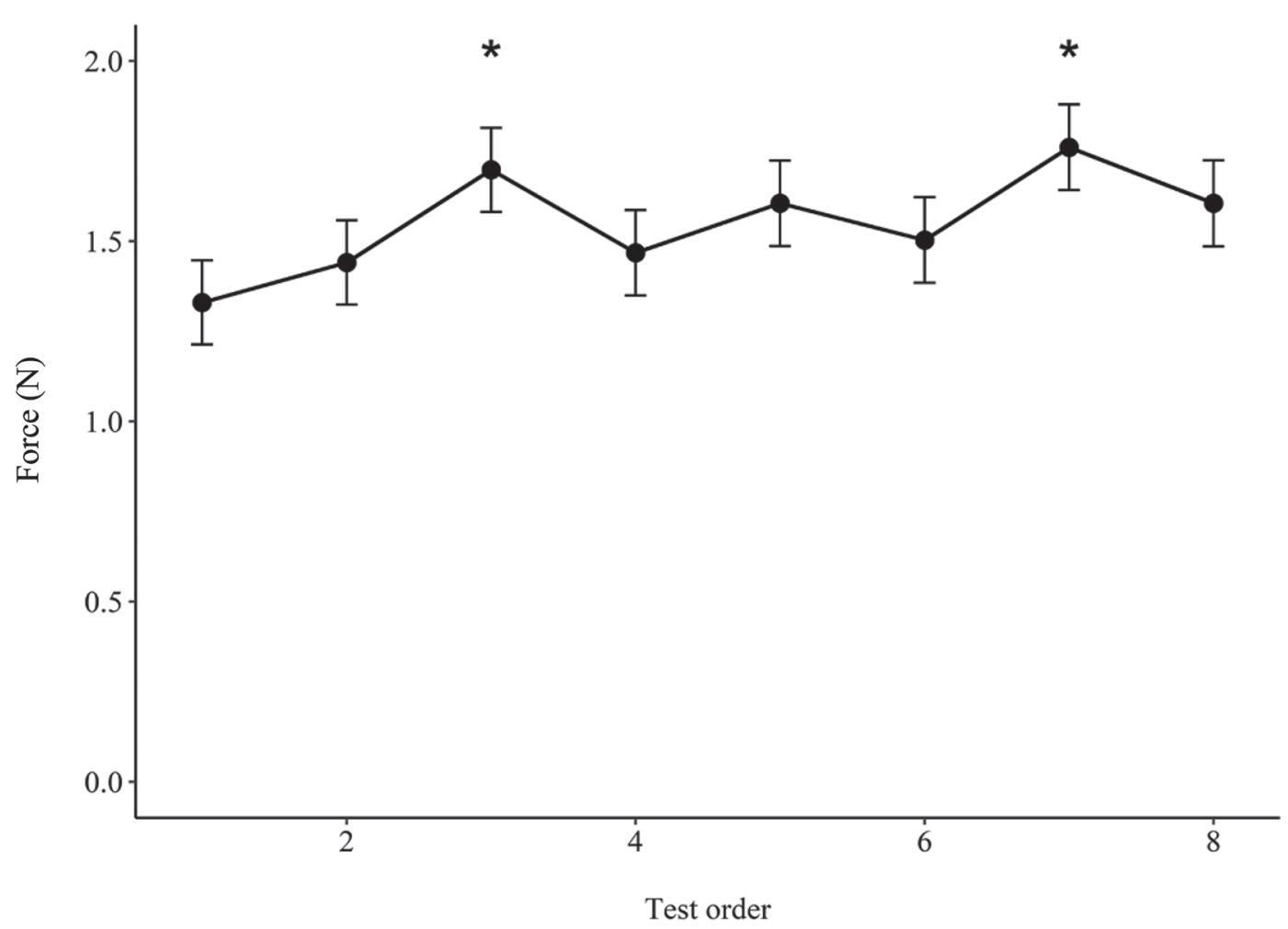

Figure 5. Disbudding wound sensitivity (force, N; LSM \pm SE) for each of the 8 tests. Sensitivity was lower on the first test than in subsequent tests $\left({ }^{*} P \leq 0.016\right)$. 


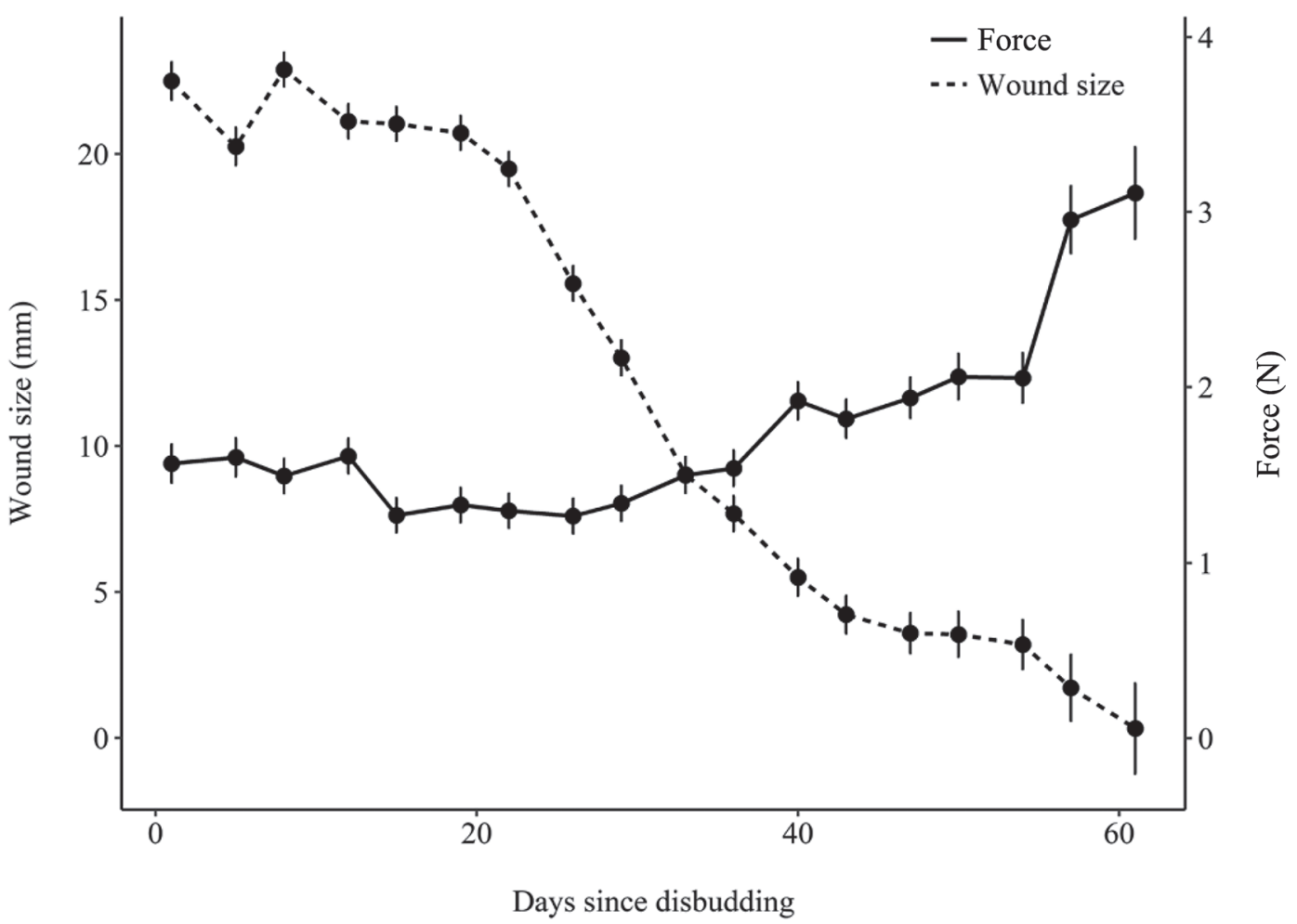

Figure 6. Mean wound size and mechanical nociceptive threshold $( \pm \mathrm{SE})$ in the days after disbudding. Wounds were scored up until they had re-epithelialized. There were 35 wounds until $36 \mathrm{~d}$, and then this number gradually declined such that only 6 and 3 wounds were scored at 57 and $61 \mathrm{~d}$, respectively.

universal complications in human burn patients and can persist for years after the wound has re-epithelialized (reviewed in Zachariah et al., 2012 and McIntyre et al., 2016). Given its important implications for welfare, sensitive assays beyond withdrawal tests are needed to assess the possibility of these long-lasting states after disbudding in goat kids.

Wounds were least and most sensitive at the middle and caudal edges, respectively. In calves, the middle (Heinrich et al., 2010; Mintline et al., 2013; Sutherland et al., 2018) and caudal (Heinrich et al., 2010) edges of the wound are less sensitive to algometry; locations closer to the eye and ear (lateral, front) were more sensitive (Sutherland et al., 2018). These findings have been related to innervation of the horn (Sutherland et al., 2018). In calves, the cornual branch of the zygomaticotemporal nerve, the major sensory structure of the horn, is closest to the lateral and front sides of the horn (Sutherland et al., 2018). In goats, however, the horn is innervated by the cornual branches of the lacrimal and infratrochlear nerves (Riebold et al., 1995; Lyon, 2018), which supply the lateral and front locations respectively; even so, these locations were less sensitive than the caudal side in our study. Thus, it remains unclear why some locations are more sensitive than others and what relevance this has, if any, for the animal's welfare. As expected, sensitivity did not differ between left and right wounds, as has also been found in calves (Heinrich et al., 2010; but see Adcock et al., 2019).

The MNT values increased over the 8 tests, perhaps indicating habituation to the algometer. A similar response was observed in sows (Nalon et al., 2016). This increase could also reflect stress-induced analgesia, a pain suppression response that occurs during or following exposure to a stressor (Ferdousi and Finn, 2018). Others have found signs of reduced nociception when animals were exposed to short-term isolation or restraint (Herskin et al., 2004). In our study, restraint could have acted as a stressor, suppressing pain responses. In contrast to our finding, others have reported a decrease in MNT over consecutive measurements in sheep (Stubsjøen et al., 2010) and dogs (Coleman et al., 2014), which the authors proposed was due to learned anticipation of the stimulus.

Welfare concerns about disbudding in goat kids have been identified during and immediately after the procedure. Our results raise additional concerns about pain experienced during the healing period and highlight the need for long-term pain mitigation strategies. In our study, no pain relief was included in the farm's SOP. 
Although this reflects typical on-farm conditions, disbudding is unequivocally painful and medication should be provided. Some information is now available on controlling acute pain in the immediate hours following disbudding (Nfor et al., 2016; Hempstead et al., 2018e), but practical strategies for managing longer-term pain have not been developed. An effective medication protocol would require a comprehensive understanding of other symptoms, in addition to hypersensitivity, that may accompany healing, such as ongoing pain and itch. Strategies to accelerate wound healing also require investigation, as our results indicate that wounds are sensitive throughout this period. In our study, wounds in 2 kids re-epithelialized as soon as 5 wk after disbudding, but the factors influencing healing time are not well understood (Adcock et al., 2019). In disbudded calves, Huebner et al. (2017) found a tendency for an aluminum-based spray to improve healing, and in human burn patients, the use of steroids reduced pain and length of hospital stay (Rowan et al., 2015). The effect of acute pain control on healing time after disbudding is unknown, but we suspect this may have a negligible influence given that the healing progression we observed is similar to what has been described in calves receiving a local anesthetic and NSAID (Adcock and Tucker, 2018b; Adcock et al., 2019). In goat kids, alternatives to the hot-iron method-caustic paste, clove oil, and liquid nitrogen - have recently been explored (Hempstead et al., 2018a,b,c). In these studies, hot-iron disbudding caused a smaller acute behavioral and physiological response than caustic paste or liquid nitrogen, and a similar response to clove oil. However, pain likely develops differently over time for each method, and further studies should compare the long-term welfare implications. In addition, hot-iron disbudding, if performed incorrectly, can cause skull and brain injury (Xyloury et al., 2000; Thompson et al., 2005).

The pain-free solution is to avoid disbudding entirely, either by raising horned animals or using polled genetics. In Europe, 19 and $53 \%$ of dairy and beef farms raise horned cattle, respectively, whereas only 1 and $7 \%$ use polled genetics (Cozzi et al., 2015). Although the rationale behind horn removal should be revisited (Zobel et al., 2019), raising horned animals in loose conditions must address issues such as increased space requirements (Loretz et al., 2004) and risk of injuries (Knierim et al., 2015). Breeding for polledness is the probable solution to welfare and management concerns (Knierim et al., 2015; Schafberg and Swalve, 2015), but other problems such as inbreeding and negative associations with production traits (Knierim et al., 2015; Windig et al., 2015) are yet to be solved.

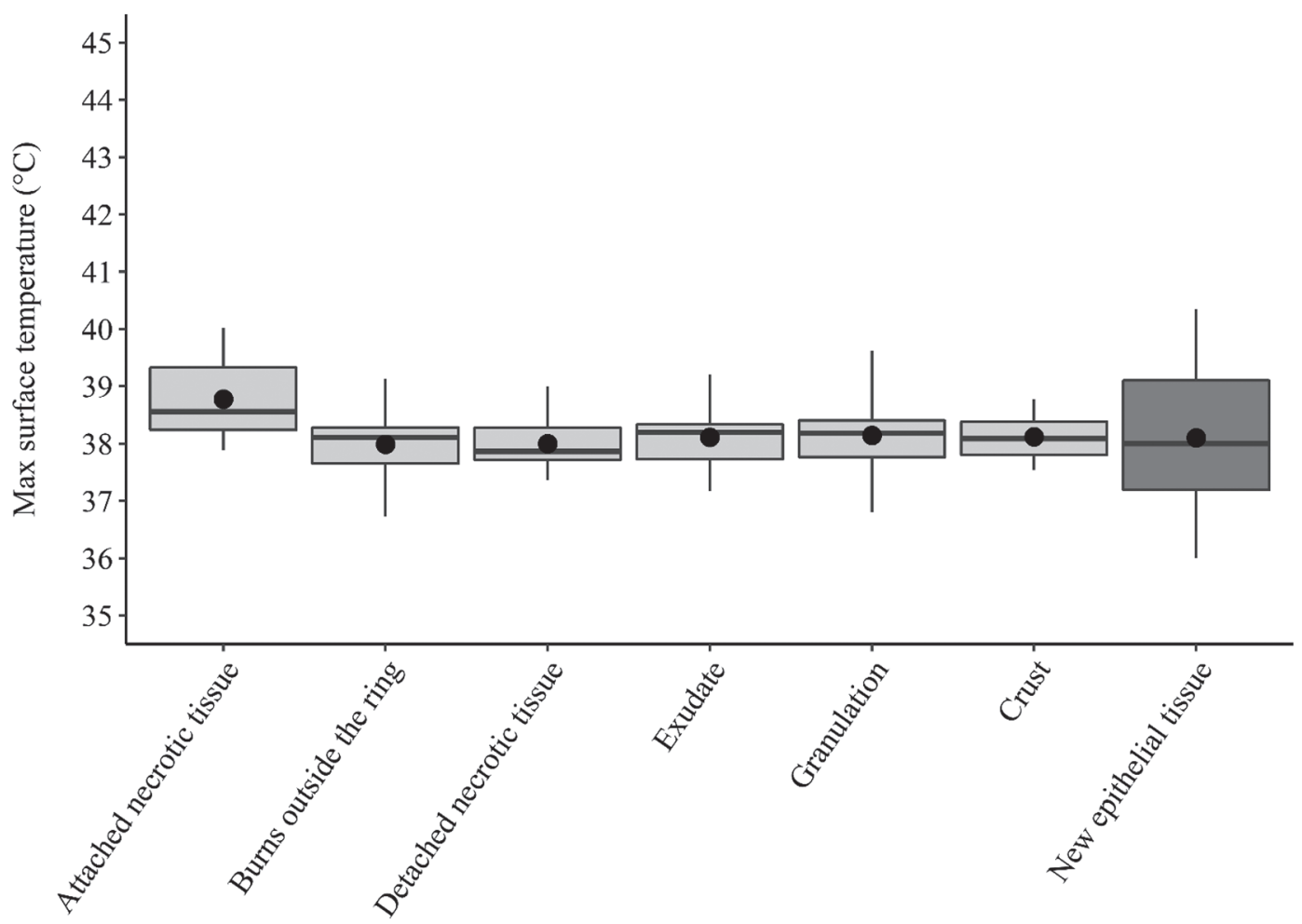

Figure 7. Maximum surface temperature $\left({ }^{\circ} \mathrm{C}\right)$ for each of the 7 tissue types present in the wound bed. Whiskers indicate the 2 nd and 98 th percentiles and circles indicate least squares means. The top and bottom of the boxes indicate the 75th and 25th quartiles, respectively. 


\section{CONCLUSIONS}

Hot-iron disbudding wounds in goat kids take 7 wk to re-epithelialize. The damaged tissue present during this period is more sensitive than newly re-epithelialized tissue, indicating that wounds are painful during the healing process. Strategies to reduce time of healing and sensitivity are clearly needed.

\section{ACKNOWLEDGMENTS}

We thank University of California Davis Goat Facility manager Rachel Conway and the goat interns for animal care and support. We are grateful to those who assisted with data collection: Emily Bingham, Katelyn Devore, Blair Downey, Katrina Gong, Melodie Lawrence, Beverley Loo, Chela Owens, Grazyne Tresoldi, Savanah Vieira, Rechelle Viernes, and Samantha Wong, all affiliated with UC Davis at the time of the study; and Marion Coste, Elodie Fabre, and Léo Roche, affiliated with AgroParisTech at the time of the study. This study was supported by USDA NIFA Multistate Research Project NC1029. We gratefully acknowledge the infrastructure support of the Department of Animal Science, College of Agricultural and Environmental Sciences, and the UC Davis California Agricultural Experiment Station. Lorenzo Alvarez's visit to UC Davis was funded by Programa de Apoyos para la Superación del Personal Académico (PASPA), Dirección General de Asuntos del Personal Académico (DGAPA), Universidad Nacional Autónoma de México (UNAM).

\section{REFERENCES}

Adcock, S. J. J., and C. B. Tucker. 2018a. Painful procedures: When and what should we be measuring? Pages 157-198 in Advances in Cattle Welfare. C. B. Tucker, ed. Elsevier, Duxford, UK.

Adcock, S. J. J., and C. B. Tucker. 2018b. The effect of disbudding age on healing and pain sensitivity in dairy calves. J. Dairy Sci. 101:10361-10373. https://doi.org/10.3168/jds.2018-14987.

Adcock, S. J. J., S. K. Vieira, L. Alvarez, and C. B. Tucker. 2019. Iron and laterality effects on healing of cautery disbudding wounds in dairy calves. J. Dairy Sci. 102:10163-10172. https://doi.org/10 .3168/jds.2018-16121.

Al-Sobayil, F. A. 2007. A new simple device for dehorning in small ruminants. Small Rumin. Res. 67:232-234. https://doi.org/10.1016/ j.smallrumres.2005.10.010.

Allen, K. A., J. F. Coetzee, L. N. Edwards-Callaway, H. Glynn, J. Dockweiler, B. KuKanich, H. Lin, C. Wang, E. Fraccaro, M. Jones, and L. Bergamasco. 2013. The effect of timing of oral meloxicam administration on physiological responses in calves after cautery dehorning with local anesthesia. J. Dairy Sci. 96:5194-5205. https: //doi.org/10.3168/jds.2012-6251.

Alsaaod, M., and W. Büscher. 2012. Detection of hoof lesions using digital infrared thermography in dairy cows. J. Dairy Sci. 95:735742. https://doi.org/10.3168/jds.2011-4762.

Alvarez, L., J. B. De Luna, D. Gamboa, M. Reyes, A. Sánchez, A. Terrazas, S. Rojas, and F. Galindo. 2015. Cortisol and pain-related behavior in disbudded goat kids with and without cornual nerve block. Physiol. Behav. 138:58-61. https://doi.org/10.1016/j .physbeh.2014.10.026.
Alvarez, L., and J. Gutiérrez. 2010. A first description of the physiological and behavioural responses to disbudding in goat kids. Anim. Welf. 19:55-59.

Alvarez, L., R. A. Nava, A. Ramírez, E. Ramírez, and J. Gutiérrez. 2009. Physiological and behavioural alterations in disbudded goat kids with and without local anaesthesia. Appl. Anim. Behav. Sci. 117:190-196. https://doi.org/10.1016/j.applanim.2009.01.001.

Casoni, D., A. Mirra, M. R. Suter, A. Gutzwiller, and C. Spadavecchia. 2019. Can disbudding of calves (one versus four weeks of age) induce chronic pain? Physiol. Behav. 199:47-55. https://doi.org/ 10.1016/j.physbeh.2018.11.010.

Coleman, K. D., C. W. Schmiedt, K. A. Kirkby, A. E. Coleman, S. A. Robertson, J. Hash, and B. D. X. Lascelles. 2014. Learning confounds algometric assessment of mechanical thresholds in normal dogs. Vet. Surg. 43:361-367. https://doi.org/10.1111/j.1532-950X 2014.12112.x.

Cozzi, G., F. Gottardo, M. Brscic, B. Contiero, N. Irrgang, U. Knierim, O. Pentelescu, J. J. Windig, L. Mirabito, F. Kling Eveillard, A. C. Dockes, I. Veissier, A. Velarde, C. Fuentes, A. Dalmau, and C. Winckler. 2015. Dehorning of cattle in the EU member states: A quantitative survey of the current practices. Livest. Sci. 179:4-11. https://doi.org/10.1016/j.livsci.2015.05.011.

David, J. A., and E. S. Chiu. 2018. Surgical debridement. Pages 3-15 in Interventional Treatment of Wounds: A Modern Approach for Better Outcomes. D. P. Orgill, ed. Springer International Publishing, Cham, Switzerland.

De Heus, P., G. Van Oossanen, M. C. Van Dierendonck, and W. Back. 2010. A pressure algometer is a useful tool to objectively monitor the effect of diagnostic palpation by a physiotherapist in warmblood horses. J. Equine Vet. Sci. 30:310-321. https://doi.org/10 .1016/j.jevs.2010.04.010.

Devgan, L., S. Bhat, S. Aylward, and R. J. Spence. 2006. Modalities for the assessment of burn wound depth. J. Burns Wounds 5:e2.

Ferdousi, M., and D. Finn. 2018. Stress-induced modulation of pain: Role of the endogenous opioid system. Prog. Brain Res. 239:121177. https://doi.org/10.1016/bs.pbr.2018.07.002.

Fulwider, W. K., T. Grandin, B. E. Rollin, T. E. Engle, N. L. Dalsted, and W. D. Lamm. 2008. Survey of dairy management practices on one hundred thirteen North Central and Northeastern United States dairies. J. Dairy Sci. 91:1686-1692. https://doi.org/10 .3168/jds.2007-0631.

Hardwicke, J., R. Thompson, A. Bamford, and N. Moiemen. 2013. A pilot evaluation study of high-resolution digital thermal imaging in the assessment of burn depth. Burns 39:76-81. https://doi.org/ 10.1016/j.burns.2012.03.014.

Harris-Bridge, G., L. Young, I. Handel, M. Farish, C. Mason, M. A. Mitchell, and M. J. Haskell. 2018. The use of infrared thermography for detecting digital dermatitis in dairy cattle: What is the best measure of temperature and foot location to use? Vet. J. 237:26-33. https://doi.org/10.1016/j.tvjl.2018.05.008.

Heinrich, A., T. F. Duffield, K. D. Lissemore, and S. T. Millman. 2010. The effect of meloxicam on behavior and pain sensitivity of dairy calves following cautery dehorning with a local anesthetic. J. Dairy Sci. 93:2450-2457. https://doi.org/10.3168/jds.2009-2813.

Hempstead, M. N., J. R. Waas, M. Stewart, V. M. Cave, and M. A. Sutherland. 2017. Behavioural response of dairy goat kids to cautery disbudding. Appl. Anim. Behav. Sci. 194:42-47. https://doi .org/10.1016/j.applanim.2017.04.001.

Hempstead, M. N., J. R. Waas, M. Stewart, V. M. Cave, and M. A. Sutherland. 2018a. Evaluation of alternatives to cautery disbudding of dairy goat kids using behavioural measures of post-treatment pain. Appl. Anim. Behav. Sci. 206:32-38. https://doi.org/10 .1016/j.applanim.2018.05.035

Hempstead, M. N., J. R. Waas, M. Stewart, V. M. Cave, and M. A. Sutherland. 2018b. Evaluation of alternatives to cautery disbudding of dairy goat kids using physiological measures of immediate and longer-term pain. J. Dairy Sci. 101:5374-5387. https://doi .org/10.3168/jds.2017-13814.

Hempstead, M. N., J. R. Waas, M. Stewart, V. M. Cave, A. R. Turner, and M. A. Sutherland. 2018d. The effectiveness of clove oil and two different cautery disbudding methods on preventing horn 
growth in dairy goat kids. PLoS One 13:e0198229. https://doi.org/ 10.1371/journal.pone.0198229.

Hempstead, M. N., J. R. Waas, M. Stewart, S. K. Dowling, V. M. Cave, G. L. Lowe, and M. A. Sutherland. 2018e. Effect of isoflurane alone or in combination with meloxicam on the behavior and physiology of goat kids following cautery disbudding. J. Dairy Sci. 101:3193-3204. https://doi.org/10.3168/jds.2017-13507.

Hempstead, M. N., J. R. Waas, M. Stewart, G. Zobel, V. M. Cave, A. F. Julian, and M. A. Sutherland. 2018c. Pain sensitivity and injury associated with three methods of disbudding goat kids: Cautery cryosurgical and caustic paste. Vet. J. 239:42-47. https://doi.org/ $10.1016 / j . t v j 1.2018 .08 .004$.

Herskin, M. S., L. Munksgaard, and J. Ladewig. 2004. Effects of acute stressors on nociception, adrenocortical responses and behavior of dairy cows. Physiol. Behav. 83:411-420. https://doi.org/10.1016/j .physbeh.2004.08.027.

Hötzel, M. J., C. Longo, L. F. Balcão, C. S. Cardoso, and J. H. C. Costa. 2014. A survey of management practices that influence performance and welfare of dairy calves reared in southern Brazil. PLoS One 9:e114995. https://doi.org/10.1371/journal.pone.0114995.

Huebner, K. L., A. K. Kunkel, C. S. McConnel, R. J. Callan, R. P. Dinsmore, and L. S. Caixeta. 2017. Evaluation of horn bud wound healing following cautery disbudding of preweaned dairy calves treated with aluminum-based aerosol bandage. J. Dairy Sci. 100:3922-3929. https://doi.org/10.3168/jds.2016-12192.

Karakuş, F., A. Düzgün, M. Karakuş, and L. Aslan. 2015. Can infrared thermography be used to predict ear tags infections in lambs? Sci. Pap. D Anim. Sci. 58:205-208.

Knierim, U., N. Irrgang, and B. A. Roth. 2015. To be or not to be horned - Consequences in cattle. Livest. Sci. 179:29-37. https:// doi.org/10.1016/j.livsci.2015.05.014.

Lenth, R. V. 2016. Least-Squares Means: The R package lsmeans. J. Stat. Softw. 69:1-33. https://doi.org/10.18637/jss.v069.i01.

Loretz, C., B. Wechsler, R. Hauser, and P. Rüsch. 2004. A comparison of space requirements of horned and hornless goats at the feed barrier and in the lying area. Appl. Anim. Behav. Sci. 87:275-283. https://doi.org/10.1016/j.applanim.2004.01.005.

Lyon, L. 2018. Local anesthesia and analgesia. Oklahoma State University, Stillwater. Accessed May 2018. https://instruction.cvhs .okstate.edu/vmed5412/pdf/14LocalAnesthesia2006b.pdf.

McIntyre, M. K., J. L. Clifford, C. V. Maani, and D. M. Burmeister. 2016. Progress of clinical practice on the management of burnassociated pain: Lessons from animal models. Burns 42:1161-1172. https://doi.org/10.1016/j.burns.2016.01.023.

Medina-Preciado, J. D., E. S. Kolosovas-Machuca, E. Velez-Gomez, A. Miranda-Altamirano, and F. J. Gonzalez. 2013. Noninvasive determination of burn depth in children by digital infrared thermal imaging. J. Biomed. Opt. 18:061204. https://doi.org/10.1117/ 1.JBO.18.6.061204.

Miccio, J., S. Parikh, X. Marinaro, A. Prasad, S. McClain, A. J. Singer, and R. A. F. Clark. 2016. Forward-loking infrared imaging predicts ultimate burn depth in a porcine vertical injury progression model. Burns 42:397-404. https://doi.org/10.1016/j.burns.2015.07.006.

Mintline, E. M., M. Stewart, A. R. Rogers, N. R. Cox, G. A. Verkerk, J. M. Stookey, J. R. Webster, and C. B. Tucker. 2013. Play behavior as an indicator of animal welfare: Disbudding in dairy calves. Appl. Anim. Behav. Sci. 144:22-30. https://doi.org/10.1016/j .applanim.2012.12.008.

Mirra, A., C. Spadavecchia, R. Bruckmaier, A. Gutzwiller, and D. Casoni. 2018. Acute pain and peripheral sensitization following cautery disbudding in 1- and 4-week-old calves. Physiol. Behav. 184:248-260. https://doi.org/10.1016/j.physbeh.2017.11.031.

Molaei, M. M., A. Mostafavi, R. Kheirandish, O. Azari, and M. Shaddel. 2015. Study of disbudding goat kids following injection of clove oil essence in horn bud region. Vet. Res. Forum 6:17-22.

Nalon, E., D. Maes, S. Piepers, P. Taylor, M. M. J. van Riet, G. P. J. Janssens, S. Millet, and F. A. M. Tuyttens. 2016. Factors affecting mechanical nociceptive thresholds in healthy sows. Vet. Anaesth. Analg. 43:343-355. https://doi.org/10.1111/vaa.12313.
Nfor, O. N., J. P.-W. Chan, M. Kere, and H.-C. Peh. 2016. Disbudding pain: The benefits of disbudding goat kids with dexmedetomidine hydrochloride. Small Rumin. Res. 139:60-66. https://doi.org/10 .1016/j.smallrumres.2016.05.005.

Pinheiro, J., D. Bates, S. DebRoy, D. Sarkar, and R Core Team. 2017. nlme: Linear and nonlinear mixed effects models. $\mathrm{R}$ package version 3.1-131, http://CRAN.R-project.org/package=nlme.

Polat, B., A. Colak, M. Cengiz, L. E. Yanmaz, H. Oral, A. Bastan, S. Kaya, and A. Hayirli. 2010. Sensitivity and specificity of infrared thermography in detection of subclinical mastitis in dairy cows. J. Dairy Sci. 93:3525-3532. https://doi.org/10.3168/jds.2009-2807.

R Core Team. 2015. R: A language and environment for statistical computing. R Foundation for Statistical Computing, Vienna, Austria.

Riebold, T., D. Geiser, and D. Goble. 1995. Large Animal Anesthesia: Principles and Techniques. 2nd ed. Iowa State University, Ames.

Rowan, M. P., L. C. Cancio, E. A. Elster, D. M. Burmeister, L. F. Rose, S. Natesan, R. K. Chan, R. J. Christy, and K. K. Chung. 2015. Burn wound healing and treatment: Review and advancements. Crit. Care 19:243-254. https://doi.org/10.1186/s13054-015 -0961-2.

Schafberg, R., and H. H. Swalve. 2015. The history of breeding for polled cattle. Livest. Sci. 179:54-70. https://doi.org/10.1016/j .livsci.2015.05.017.

Smith, C. M., and M. D. Sherman. 2009. Goat Medicine. 2nd ed. Wiley-Blackwell, Ames, IA.

Stubsjøen, S. M., P. S. Valle, and A. J. Zanella. 2010. The use of handheld algometer as a method to measure mechanical nociceptive thresholds in sheep. Anim. Welf. 19:31-36.

Sutherland, M. A., F. J. Huddart, and M. Stewart. 2019. Short communication: Evaluation of the efficacy of novel disbudding methods for dairy calves. J. Dairy Sci. 102:666-671. https://doi.org/10 $.3168 /$ jds.2018-15230.

Sutherland, M. A., J. Larive, V. Cave, and G. Zobel. 2018. Behavioural and physiological responses to clove oil injected under the horn bud of calves. Appl. Anim. Behav. Sci. 204:29-36. https://doi .org/10.1016/j.applanim.2018.03.004.

Thompson, K. G., R. S. Bateman, and P. J. Morris. 2005. Cerebral infarction and meningoencephalitis following hot-iron disbudding of goat kids. N. Z. Vet. J. 53:368-370. https://doi.org/10.1080/ 00480169.2005.36578.

Valdmanis, L., P. Menzies, and S. Millman. 2007. A survey of dehorning practices and pain management in goats. Page 181 in Proc. 41st Congr. Int. Soc. Appl. Ethol., Merida, Mexico. International Society for Applied Ethology, Edinburgh, Scotland.

Van der Saag, D., S. Lomax, P. A. Windsor, C. Taylor, and P. J. White. 2018. Evaluating treatments with topical anaesthetic and buccal meloxicam for pain and inflammation caused by amputation dehorning of calves. PLoS One 13:e0198808. https://doi.org/ 10.1371/journal.pone.0198808.

Winder, C. B., S. J. LeBlanc, D. B. Haley, K. D. Lissemore, M. A. Godkin, and T. F. Duffield. 2016. Practices for the disbudding and dehorning of dairy calves by veterinarians and dairy producers in Ontario, Canada. J. Dairy Sci. 99:10161-10173. https://doi.org/10 $.3168 /$ jds.2016-11270.

Windig, J. J., R. A. Hoving-Bolink, and R. F. Veerkamp. 2015. Breeding for polledness in Holstein cattle. Livest. Sci. 179:96-101. https: //doi.org/10.1016/j.livsci.2015.05.021.

Xyloury, E., O. Sabatakou, and T. Sakellariadi. 2000. Meningoencephalitis caused by thermal disbudding in goat kids. Bull. Hellenic Vet. Med. Soc. 51:308-309. https://doi.org/10.12681/jhvms.15692.

Zachariah, J. R., A. L. Rao, R. Prabha, A. K. Gupta, M. K. Paul, and S. Lamba. 2012. Post burn pruritus - A review of current treatment options. Burns 38:621-629. https://doi.org/10.1016/j.burns 2011.12.003.

Zobel, G., H. W. Neave, and J. Webster. 2019. Understanding natural behavior to improve dairy goat (Capra hircus) management systems. Transl. Anim. Sci. 3:txy145. https://doi.org/10.1093/tas/ txy145. 